Article

\title{
Does the Energy Label (EL) Matter in the Residential Market? A Stated Preference Analysis in Barcelona
}

\author{
Carlos Marmolejo-Duarte ${ }^{1, *}$ and Marina Bravi ${ }^{2, *}$ \\ 1 Centre for Land Policy and Valuations, Barcelona's School of Architecture, Technical University of Catalonia, \\ 08034 Barcelona, Spain \\ 2 DIST (Interuniversity Department of Regional and Urban Studies and Planning), Politecnico di Torino, \\ Torino 10125, Italy \\ * Correspondence: marina.bravi@polito.it (M.B.); carlos.marmolejo@upc.edu (C.M.-D.)
}

Received: 28 March 2017; Accepted: 7 June 2017; Published: 16 June 2017

\begin{abstract}
Energy performance in buildings has become a milestone in EU environmental policy in the last 15 years. Nonetheless, in some countries such as Spain the full acceptance of the Energy Performance of Buildings Directive is still relatively rare and novel, with little evidence as to how relevant it is in the real estate market. There are different reasons for this phenomenon: on the one hand, the real estate crisis has paralyzed the completion of most of the works in new / refurbished efficient buildings (which renders it impossible to use revealed preference methods); on the other hand, information is not complete and the consumer's perception of the relevant cost/benefits could be incorrect. For this reason, assessing the trade-off between the energy label and other specific attributes of the housing market has become important. To that end, a choice experiment following an RPL (Random Parameter Logit) model was employed. This form is suitable to accommodate various empirical situations where the assumptions of the Conditional Logit model have to be relaxed. Results suggest that the Energy Label (EL) does matter in the real estate market in relation to other residential attributes. Marginal willingness to pay for an " $\mathrm{A}$ " label instead of an " $\mathrm{E}$ " is significantly higher than the stated savings in energy costs. The respondents' utility function seems to be also influenced by their educational level, as well as by their preference to own a house as opposed to renting it.
\end{abstract}

Keywords: Energy Label (EL); Energy Performance Certifications (EPC); choice experiments; buildings' energy performance; Random Parameters Logit (RPL); housing policies; unlabelled choices

\section{Introduction}

Considering that buildings make up $40 \%$ of the total energy consumption [1] in the EU, the Community policy established the adoption of an Energy Label (EL). The purpose is to provide transparency and encourage informed real estate transactions, thus promoting efficient buildings by using a simple A-G (high to low efficiency) ranking associated to the level of energy consumption and $\mathrm{CO}_{2}$ emissions under "normal" use conditions. In other words, the EL is an interesting measure to overcome the lack of information barrier by providing consumers with the necessary input. In fact, buildings' energy efficiency is an intangible attribute that results from the combination of both exterior (i.e., orientation) and interior components. Even more, the different architectural and technical attributes with an impact on energetic performance may be hidden or have an indirect influence. Overall, this situation makes it difficult for non-specialists such as households to assess the buildings' quality. In order to break this lack of transparency (or information asymmetry), the EU has promoted the universalization of the EL in the real estate market by means of the Energy Performance of Buildings Directive (EPBD-2002/91/CE; 2010/31/UE). This policy promotes energy-informed real estate transactions, under the hypothesis that buildings with high-energy efficiency will be 
preferred by the demand in terms of occupation rates and prices, thus promoting a sustainable development. In order to identify effective policy measures to incentivize more investment in buildings' energy performance, it is necessary to collect information on the factors influencing households' investment decisions as well as their willingness to pay for the resulting improvements. Nonetheless, energy efficiency indicators such as the Energy Label (EL), which derive from Energy Performance Certifications (EPC), are not isolated attributes influencing choices and prices. For this reason, it is also necessary to understand the actual role they play when other features are present. This paper tries to explore household preferences in Barcelona in order to study if the EL is important to the consumer, the amount of marginal WTP for energy-qualified apartments, and if there are some socio-economic or behavioural characteristics that are able to explain the heterogeneity of preferences in this regard.

In Spain, the latest transposition of the EPBD (RD 314/2006, RD 1027/2007; RD 235/2013) occurred precisely within the same timespan as one of the longest real estate crises, characterized by the absence of energy-efficient building completions, which rendered it impossible to observe consumer preferences using methods based on revealed preferences. Furthermore, according to Marmolejo [2], although it is mandatory to include the EPC EL class in real estate listings for sale or rent, only $12 \%$ of all listings in Barcelona clearly state the apartment's energy class. Due to these reasons, choice experiments (CE) have been selected as the method to be used in this work so as to elicit preferences of both tenants and buyers in the housing market of Barcelona. A CE consists of having a group of individuals (e.g., potential buyers or tenants) select their preferred option (i.e., to buy or lease) when presented with different alternatives (e.g., an apartment with different attributes including the EPC and its levels-classes). Then, through statistical analysis of their preferences, and with the help from a discrete choice model, the marginal utility supporting each characteristic of the evaluated options is inferred. The experiment reported here is made up by four steps: determining the number of attributes and levels; designing the apartment (e.g., combination of levels of attributes); managing a mixed Web and face-to-face survey; and analyzing the results using specific econometric models.

Despite the fact that the EPC EL is quite recent in the Spanish residential market, respondents were ready to pay for an energetic improvement. Marginal WTP is, as a matter of fact, higher than the offered energy saving. This surplus may be related to the environmental benefits generated by the $\mathrm{CO}_{2}$ emission reduction. At the same time, energy efficiency seems to be more important than other attributes such as the active thermal conditioning, the amenities of the condominium where the offered apartment is located or even additional private spaces, which failed to appear as being significant in the models. On the other hand, both the educational level and the tenure preference seem to play a significant role, revealing important implications for the EPC's dissemination policy and its integration into the broader framework of housing policy.

This paper is organized as follows: first, review of the literature; second, explanation on the methodology and case study; and third, presentation of parameters and results. In the final remarks, the findings and implications are discussed.

\section{Literature on the Buildings' Energy Performance Valuation with the Emphasis on Stated Preference Methods}

In the residential market a considerable number of studies use hedonic pricing to estimate the marginal price of green labels, including that of the EPC [2,3]. The pioneering work of Brounen and Kok [4] in The Netherlands found a marginal increase of $10 \%$ in transaction selling prices for " $\mathrm{A}$ " ranked houses and $-5 \%$ for " $\mathrm{G}$ " houses in relation to that rated with " $\mathrm{D}$ ". The study of Hyland et al. [5] in Ireland found that the marginal price of the EPC is higher in selling than in leasing prices. For example, on average class " $\mathrm{A}$ " translates into a 9.3\% increase (compared to class " $\mathrm{D}$ ") in the selling price, compared to $1.8 \%$ in the leasing price. By the same token, class " $G$ " generates a $10.6 \%$ decrease in selling prices (compared to " $\mathrm{D}$ "), but only a 3.2\% decrease in leasing prices. The deeper impact of energy efficiency in the selling versus rental market for other green labels and for commercial property has also been studied [2]. As it will be seen, tenure preference also seems to play a role in the 
study reported here. Departing from listing prices, Mudgal et al. [6] report hedonic estimations for different cities across Europe. Their findings stress the unequal incidence of EPC both across countries (in Wien, EPC measured as linear variable increases of 10-11\% with respect to the selling price of houses, but only $0.4 \%$ in Oxford) and within them (both in Austria and Belgium the incidence is higher in hinterland areas rather than in capital cities). The authors provide some explanations regarding the price of energy in relation to housing prices, income, weather, construction techniques, regulations, and environmental concerns. For these reasons, it is necessary to valuate this factor in mild weather cities, such as Barcelona, where this topic remains highly unexplored. In the UK the work of Fuerst et al. [7] reports a market premium of $5 \%$ for Class " $\mathrm{A}$ " houses and penalties of $7 \%$ for Class " $\mathrm{G}$ " houses in relation to the medium " $\mathrm{D}$ " rate.

At the same time, an emergent body of research employs stated preference methods (including choice experiments). The latter allows for the identification of the latent utility of green attributes by estimating the trade-off between energy efficiency and other characteristics of the dwelling. It becomes useful when actual transactions with revealed preferences are not available, as is the case of Spain.

In The Netherlands, Poortinga et al. [8] used a paper-based conjoint analysis where respondents declared the acceptability level of some energy-saving measures in a Likert scale. In this way, the authors identified the trade-off between energy-saving appliances and the willingness to change consumption behavior. Their results suggest that energy-saving strategies (technical upgrades, different use of products) were preferred over behavioral measures (i.e., turning the lights off when not in use) and shifts in consumption (except for low-income individuals, who preferred changing their energy-saving habits instead of making unaffordable investments). Nevertheless, energy saving in the residential context was more acceptable than transport energy-saving measures, especially in the case of young and wealthy respondents. Interestingly, this study also highlighted that energy-saving measures may be more acceptable if they are deemed evident and beneficial for the environment.

In a similar line, Sadler [9] used two paper-based choice experiments to assess preferences for home renovations and heating systems in Canada. Each "choice set" was formed by alternative heating systems already available in the market; and the choice of home renovation with and without energy retrofits. Her results highlight that households prefer energy-efficient renovation over renovations without energy retrofits. The relationship between capital expenditure of renovations and heating cost savings suggest a discount rate of $21 \%$ per annum and $9 \%$ when only heating system improvements are involved. Nonetheless, renovations with energy retrofits seem to be primarily driven by the necessity to refurbish the property rather than the interest in achieving energy savings. In this regard, Achtnitcht and Madlener [10] found that households willing to improve the energy efficiency of their homes are those which are willing to pay for what they think is a profitable investment and which consider that some benefit (e.g., tax savings) can be reaped of the planned renewals. Therefore, energy improvements take place only when they become necessary so as to replace old systems and it is only at that moment, and not before, when the energy-saving benefits are assessed.

In Switzerland, Banfi et al. [11] used telephone-based choice experiments to determine willingness to pay for energy-saving measures in residential buildings. Each choice task consisted of reading a card that listed the features of the actual house and those of another dwelling and having to choose the one which was preferred out of the two alternatives. Offered improvements included air renewal systems and insulation of windows and facades. Their analysis indicates that consumers significantly value green attributes, due to the energy savings and environmental benefits they bring along; even though other attributes, such as thermal comfort, air quality, and noise protection, are considered. Respondents were willing to pay an extra 3\% for an improvement in the facade insulation, $8 \%$ for the ventilation system, and $13 \%$ for windows. The larger marginal willingness to pay for this latter attribute highlights the importance of noise protection.

Using the same approach, Kwak et al. [12] arrive to the same conclusion in Korea. Both studies stress that energy efficiency is relevant, not only in terms of energy cost savings, but also because the consumers' statements are influenced by environmental concerns. To compare the relevance 
of financial benefits against environmental ones, Achtnicht [13] uses face-to-face computer-assisted choice experiments to assess the consumers' energy preferences in renovations with energy retrofits resulting from insulation and heating systems. An important novelty in his study is the inclusion of the actual savings in cost and $\mathrm{CO}_{2}$ emissions, as well as professional energy consultancy services. The respondents were provided with two hypothetical measures of upgrades regarding their heating supply and usage respectively, from which they could choose. The results stress the important role played by environmental attributes in the choice of heating systems as opposed to the case of insulation. In the same line of Poortinga et al. [8], it becomes apparent that people pay attention only to attributes where energy consumption is direct or evident (i.e., fuel-based devices) but not to those that may have a large contribution to energy efficiency but which remain invisible for non-professionals (i.e., wall insulation). These conclusions are important for public policy since households seem to have developed an environmental responsibility, although they are not aware of the building's performance and its implications in energy efficiency.

Cost saving seems to be a major argument in energy-efficiency renewals; nonetheless, such long-term savings are not granted at all for a number of reasons. To explore this issue from the perspective of the consumers' risk aversion, Farsi [14] used a choice-based experiment, so as to determine the uncertainty involved in energy efficient capital expenditures. Uncertainty emerges from divergences between theoretical and real savings, since the latter are influenced by users' behavior, instability in energy pricing and the fact that technological progress may give rise to premature obsolesce in previously released technology. In each choice situation the respondents were provided with a choice card including the characteristics of the offered alternative along with those of their current housing. Said features consisted of window and façade insulation, ventilation, and monthly rent changes. His results suggest that apartment tenants perceive the investment in new insulation and high-efficiency ventilation systems as risky, because of the fact that such systems are new in the market. These findings are consistent with those of Sadler [9], where high discount rates suggest a risk which is perceived as high, as well as the willingness to amortize the investment quickly. Conversely, traditional systems are perceived as reliable, thus implying a moderate risk in economic terms. Overall, this entails an important challenge in the communication policy of new energy-efficient appliances and stresses the potential of traditional energy passive systems.

As mentioned in the introduction, energy efficiency in real estate is an intangible attribute influenced by a number of characteristics which become perceivable by means of energy labels. Therefore, analyzing such a proxy and its rivalry with other attributes is important from the perspective of sustainable development policies. Heinzle et al. [15] take into consideration both aspects in their study based in Singapore, where buildings, according to the "Green Mark" (GM) scheme, can be labeled as: "GM Certified" (if they meet a minimum efficiency score level), "GM Gold", "GM Goldplus", and "GM Platinum" (if they meet a maximum efficiency score level). The authors use adaptive choice-based-conjoint (ACBC) methods, the latest refinement in conjoint analysis, which is suitable when respondents employ non-compensatory decision-making processes (ACBC holds that in manifold choice tasks (involving many attributes), respondents first eliminate from their consideration set those alternatives which have unacceptable levels, and secondly, they make choices among products which are consistent with such screening rules.). Their findings reinforce those of Addae-Dapaah and Chiech [16] and Zalajeska-Jonsoon [17], since green attributes are not the most relevant when consumers are choosing a house. Factors such as price, area, location, orientation, distance to rapid transit systems, and services seem to be more important than the EL certificate. Nonetheless, such green labels seem to be significant when explaining willingness to pay, since the marginal value of "GM Certified level" makes up 3.78\%; and 7.98\%, in the case of "GM Platinum level".

The research reported here is different since it explores the tradeoffs between the EL (EPC) ranking and other residential attributes while selecting a standard city apartment and taking into consideration that energy efficiency is enclosed in the EPC scheme. Moreover, the aim is to interpret the heterogeneity 
of preferences considering the different behavior of owners and renters, as well as other characteristics of the respondents.

\section{Methodology and Case Study}

From its origin until today, choice experiments (CE) have been seen as a way to study a system of implicit values when choosing an option within a finite set of alternatives [18]. CEs consist of making a group of individuals undertake a task in which they are faced with the choice, among a finite set of alternatives, of their preferred option (usually a product or service). These alternatives are usually referred to as "the choice set" and, from a cognitive point of view, their comparison (followed by the final choice) represents the task that the respondent is called to accomplish. Each alternative is made up from attributes (e.g., number of bedrooms in an apartment, or the EL) and there are different levels for each attribute (e.g., 1, 2, or " $\mathrm{A}$ ", “ $\mathrm{B}$ ", “ $\mathrm{C}$ ” rankings). So, this technique allows to: (a) detect which attributes are more relevant for the potential or actual users; (b) identify the preferred levels inside each attribute; (c) analyse the interaction between different levels; and (d) simulate the preference for a new project.

CEs have a number of benefits in favour of robust results because: (1) choice tasks are based in comparisons among a finite set of alternatives just like in the actual transactions in the real estate market; (2) in choosing a given alternative, an individual explicitly relinquishes the others, thus making it possible to identify the trade-off between levels and attributes; (3) individuals express their preferences in an indirect manner reducing the strategic bias of self-explanatory methods; and (4) this approach allows to impose the ceteris paribus clause for the remaining relevant characteristics, which is consistent with highly segmented markets such as the residential market.

From a theoretical standpoint, CEs pertain to the random utility theory (RUT) field [19], which considers that utility driving choice decisions is made up by a deterministic part (i.e., attributes/levels of the chosen option or characteristics of the respondent) and other stochastic (i.e., idiosyncratic) factors. Consistently, CEs help to explain variability in behaviour response in a sample of population considering the latent utility in choices. CEs construct a hypothetical scenario where individuals reveal what they would choose in a real situation, so that what is declared are intentions and not actions. According to Ajzen's [20] “Theory of Planned Behavior", the individual's behavior (e.g., choosing a given real estate development in a real situation) is determined by the intention to perform a task (i.e., an individual's positive or negative assessment of choosing a given product), a subjective norm (i.e., an individual's perception of social pressure from other individuals' preferences), and perceived behavioral control (i.e., an individual's perception of difficulties in obtaining the desired option). Therefore, in CEs the last two features might be underrepresented owing to their contingent nature and there are no warranties that in real situations the respondents will choose what they previously declared as their favorite alternative. This issue is known as "hypothetical bias" (HB) and it is common to stated preference techniques. HB is defined as the difference between hypothetical and actual statements of value (or willingness to purchase), while actual statements of value are obtained from experiments with real economic commitments. According to Ehmke et al. [21] a number of reasons have been argued for the existence of such a bias: strategic response, uncertainty about one's value for the assessed good, commitment cost, social desirability bias. These authors have found that the bias is not uniform across cultures but tends to be sharper in the U.S. but smaller in countries such as Niger, France, and China; so the bias seems to be larger in well-developed economies. To the best of our knowledge, no study has quantified HB in the EPC EL residential markets; though in the meta-analysis carried out by List and Gallet [22] the HB was in the region of a factor of 3.5 (stated/actual value) and in rare cases it reached a factor of 10. This results are in line with the National Oceanic and Atmospheric Administration's blue ribbon panel (NOOA's BRP) recommendation, which suggested that hypothetical bids be deflected using a "divide by 2 " $[23,24]$ approach when using the contingent valuation method (another technique affiliated to the stated preference family). In addition to that, researchers have found $[22,25,26]$ that $\mathrm{HB}$ tends to be smaller when: (1) goods assessed are private, 
as opposed to public; (2) people are asked to state their willingness to pay (WTP) instead of their willingness to accept (WTA); (3) experiments are realistic (i.e., payment vehicles are familiar and people rely on the feasibility to provide the attributes of the assessed goods) (In addition to that, researchers have designed ex ante and ex post techniques to reduce HB. The first includes "cheap talks" [27] and reminders of individuals' budgets, while the second includes special statistical techniques, such as stochastic frontier regressions [28]); and (4) individuals are carefully selected so as to ensure convenient experience and appropriate demographics.

All these reasons support the use of CEs in this work, in the absence of data about actual transactions, since: (1) usually, people choose between a finite set of alternatives when looking for a new apartment; (2) houses are private goods and people are used to paying a price according to their attributes; (3) the EL (EPC) ranking is usually declared in the actual market offers; (4) a WTP approach is used instead of WTA after properly informing about economic and environmental implications of the EL classification; (5) a clear and realistic payment vehicle has been designed and the amount is in keeping both with monthly mortgage and rent payments, with which people are already familiar, and (6) respondents were carefully selected so as to ensure the necessary cognitive resources to perform the task, as will be discussed further in the next section. Moreover, List et al. [29] recognise that CEs are reliable proxies for private goods market research because respondents are used to paying for the product attributes as a whole; and, as a matter of fact, they constitute an extension of binary discrete choice methods also recommended by NOOA's BRP.

Data gathered by means of surveys are analysed with conventional econometric models. The observed component of utility associated with different alternatives is usually defined as a function involving a simple linear combination of attributes and parameter estimates. With the help of a discrete choice model, the marginal utilities are inferred for each attribute of the considered options.

The experiment reported here is made up by the following: determining the number of attributes and levels; designing the product (e.g., combination of levels of attributes); managing a mixed Web and face-to-face based survey applied to a sample coming from the relevant population and analyzing the results using specific econometric models as explained in Section 3.3.

\subsection{Attributes, Levels, and Experimental Design}

Perhaps the selection of attributes and levels to be included in the experiment is the most critical point in the design of choice experiments. According to Marmolejo and Ruiz [30] (p. 83) this method "does not provide elements that enable the identification of the attributes/levels to be evaluated"; therefore, they suggest the use of previous focus groups in order to assess such levels. Other authors use alternative approaches. For example, Sadler [9] selects the attributes from the heating systems registered in the housing statistics; Earnhart [31] studies the architectural features that shape the dominant housing type in the area analyzed; Zalajeska-Jonsson [17] identifies the attributes that have previously been reported as relevant in the residential choice; Heinzle et al. [15] analyze real estate advertising so as to identify relevant attributes.

The second issue is the determination of the number of attributes to be used in the choice experiments taking into account two extremes. On the one hand, a large number of attributes reduces the risk to exclude those relevant to residential choice, whilst increasing the cognitive effort with heavy consequences due to the effects of bias; and, on the other hand, having only a few attributes increases the aforementioned risk but reduces the cognitive burden.

Kastner and Stern [32] stress that, in the decision theory framework, people do actually consider a relatively reduced number of elements when choosing among alternatives. For these reasons, in this experiment, the identification of both the number of attributes and the alternatives has been carried out according to the following steps: 
1. On the basis of new developments' listings, the main marketing attributes were detected.

2. Using a factorial and cluster analysis and starting from 25 attributes (and their relevant levels) based on 4019 real estate offers of recent completions, the typical new apartment in Barcelona was identified.

3. Previous local research on the relevance of residential attributes in Spanish real estate was reviewed $[2,33]$.

Once the relevant attributes had been identified with the help of a focus group (Said group was made up by engineers, architects, economists, and sociologists with experience in the analysis of real estate markets, buildings' energy label, and real estate appraisal.), a decision was made to eliminate all those which were related to location, since the EPC scheme does not take this attribute into consideration-which does not mean that it is unimportant. On the assumption that location corresponds to that required by the respondents, the standard apartment was considered to have: three bedrooms, a living room, a kitchen, one complete bathroom, as well as the following additional and alternative attributes/levels:

1. Condominium amenities. Two levels: storage room or storage room plus swimming pool. It is common that new developments include such attributes even when they are targeted at mediumand medium-low income population segments.

2. Additional private spaces. Two levels: terrace and powder room or balcony plus complete bathroom. In general, new developments with three bedrooms do include two complete bathrooms; nevertheless, a trade-off between the spaces "additional bathroom/powder room" and "balcony/terrace" could be present. Privately-used open spaces are important in Mediterranean real estate markets.

3. Quality of finishings. Three levels: basic, standard, and high quality. For each level, a description was given regarding the kind of material used in the walls, floors, and kitchen.

4. Active conditioning. Two levels: (radiant) heating and heating plus air conditioning (heating pump).

5. Energy label. Three levels: " $\mathrm{E}$ " (the minimum level, according to the current building regulation in Spain), " $\mathrm{C}$ ", and " $\mathrm{A}$ ". Participants were informed about monetary energy savings and $\mathrm{CO}_{2}$ emissions reduction for the latter two classes in relation to the worst (" $\left.\mathrm{E}^{\prime \prime}\right)$. Despite the fact that the use of precise values is not mandatory in the literature, both savings and emission reduction are used in this experiment, which correspond to the stated improvement for the specific apartment type. For that reason, the results reported by García-Navarro [1] and Barboza [34] have been properly adapted to the local energy costs. The $\mathrm{E} \rightarrow \mathrm{A}$ improvement entails approximately $30 € /$ month in savings and a reduction of 2.3 tons of $\mathrm{CO}_{2} /$ year for the offered apartment. The $\mathrm{E} \rightarrow \mathrm{C}$ change allows savings of $20 € /$ month and means a reduction of 1.6 tons of $\mathrm{CO}_{2} /$ year. In order to give a more tangible picture of the reduction in $\mathrm{CO}_{2}$ emissions, the equivalent distance covered by a city car was depicted. It is worth highlighting that the official EPC scheme, as implemented in Spain, informs about the efficiency class letter, the non-renewable primary energy in $\mathrm{kWh} / \mathrm{m}^{2} /$ year and $\mathrm{kg}$ of $\mathrm{CO}_{2} / \mathrm{m}^{2} /$ year. Nevertheless, such technical units are clearly aimed at specialists and not at the general public. That is the reason why such units have been translated into more comprehensive ones in this experiment.

6. Price charging. Respondents were informed about the fact that constructions using high-quality finishings and energy-efficient attributes (i.e., wall/window isolation) increased the price of the building. For that reason, a price charge up to $130 €$ would be added to the monthly payment of rent or mortgage (In Barcelona, during the last few years, monthly installments of mortgages and monthly rent payments are more or less equal). The price charge has been calculated by adding production and development costs for different levels of finishes and energy classes. To transform these marginal increases into monthly payments, a direct capitalization has been used with a $4 \%$ yield (which is the usual standard in Barcelona for these kind of apartments). The price charge allocation is, thus, conditional to the finishings, thus avoiding the possibility to 
present an unrealistic combination of low-quality apartments with high prices. The assumption is that respondents value the trade-off between price charge (marginal price) and the overall benefits derived from different apartment attributes.

In order to render the choice experiments easier, most of the attributes/levels were transformed into icons, using the info graphics which are commonly used in real estate listings (Figure 1).

Apartment 1

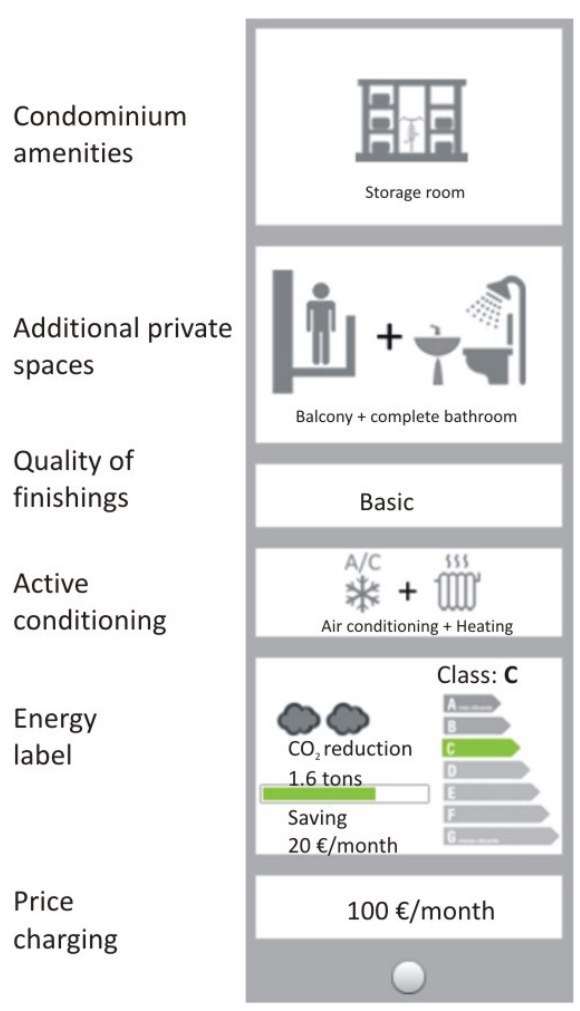

Apartment 2

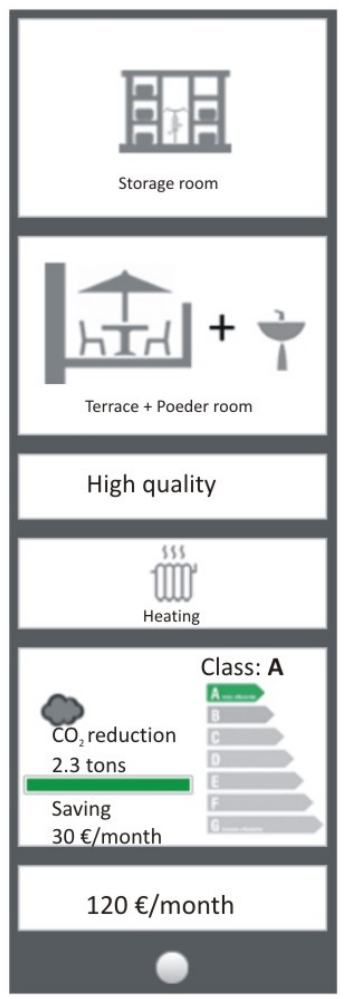

Apartment 3

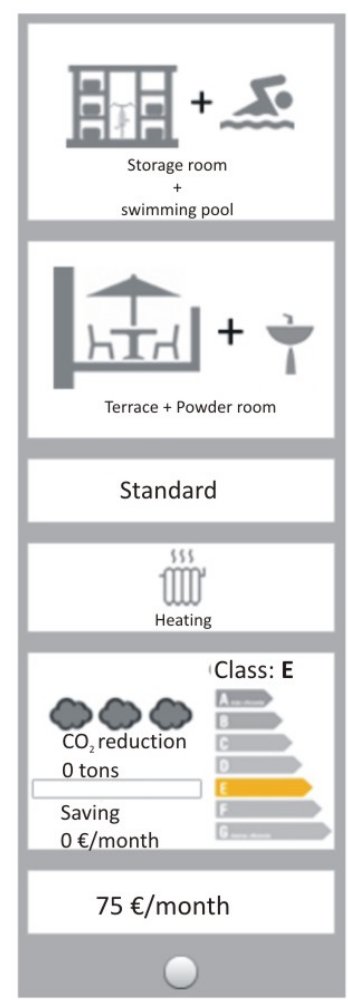

Figure 1. Unlabeled choice experiment display compiled by the author (Price to be added to the monthly rent or mortgage installment).

The number of possible combinations that respondents were faced with was reduced using a fractional factorial design. Such a procedure consists of designing a sample of the number of possible combinations that strategically combine high attribute levels in order to reduce cognitive effort and to increase the possibilities to maintain the interest in repeated choice tasks (in this case, there were four of them). In order to capture possible interactions (i.e., a multiplicative increase in utility produced by a combination of different levels), the design followed a balanced overlap method [35] (This method is an intermediate position between the random and complete enumeration. Therefore, it inherits the benefits of both of them: the possibility to capture interactions and the preservation of the accuracy of the main effects.) with a randomized combination of the relevant attributes. This kind of experimental design is justified by the valuation purpose, as described above. This is aimed at assessing the willingness to pay and the interest related to the building energy label by considering some standard architectonic attributes which are normally included in the choice of a city apartment. The estimated parameters are not specific to a sub-market, but are rather considered to have general validity. Using a computer-assisted and Web-managed interview (The interview was conducted with CBC-SSI of Sawtooth Software ${ }^{\odot}$ ), the efficiency of the design was tested before applying the survey. 


\subsection{Interview Structure and Relevant Population}

The choice experiment was included in a larger survey with the following structure:

1. Contextualization. The goal is to understand the previous knowledge of respondents about the EPC scheme, as well as their energy consumption and sustainable habits and their satisfaction about the status quo option.

2. Choice experiment. Each respondent was asked to perform four choice tasks after being clearly informed about each of the attributes and levels used in the different apartment alternatives included in the choice sets. In doing so, complementary graphic material was used in order to visualize the quality of the finishings.

3. Willingness to pay (WTP). Respondents were asked to state directly their willingness to introduce an additional payment to their monthly lease or mortgage installment in order to rent or buy a Class " $A$ " apartment versus another similar apartment ranked as Class " $E$ " after being informed, again (in comprehensive illustrative units), on the energy savings and environmental implications of such an upgrade. This information allows us to test the consistency of the choice experiments' results as further discussed (The format of this item was a close-ended question with a follow-up in which respondents were asked to declare if they were willing to pay more or less than 30 Euros/month (the exact energy savings amount) and, depending on the "yes/no" answer, they declared the WTP around this amount (plus or minus).

4. Socio-economic profile. In order to test whether preferences depend on individuals' heterogeneity, and socio-economic characteristics (SECs) such as gender, age, income, professional status, and educational level were recorded.

Surveys were conducted in the spring of 2016, excluding the hottest/coldest seasons in order to avoid overstatements. Half of them were administered by the Web; and the other half, by a face-to-face computer-aided interview system. Said strategy allows for a compensation between the inconveniences posed by both methods: face-to-face interviews may give rise to a complacency bias, but allows clarification of those questions that might be difficult to understand for some individuals and they grant access to non-digital users; at the same time, Web-based surveys allow the respondents to express their opinion freely.

Participants were recruited among the different neighborhoods of the city of Barcelona and its suburban municipalities in order to cover socio-demographic differences. In total, the analysis consists of 1000 choice tasks from 250 respondents (after discarding 76 incomplete or incoherent surveys). Taking into consideration the number of households in the area of study, the margin of error is $6.2 \%$ for a $95 \%$ confidence level; therefore, this sample is large enough for an exploratory study. It should be noted that similar studies use smaller samples: Poortinga et al. [8] use 455 surveys for all of The Netherlands; Sadler [9], 600 for all of Canada; Banfi et al. [11], 305 for all of Switzeland; and Heizle et al. [15], only 62 for Singapore, with two times the population of the paper's case study. Finally, it is worth reminding that each respondent conducted four CEs. This data structure requires a specific modeling as explained below.

\subsection{Unlabeled Choices and the Random Parameter Logit (RPL) Model}

In general, the case of dependent data occurs when individual observations are correlated. This dependence can arise from the existence of a hierarchical structure (nested data) and often characterizes the situation in which the interview occurs (grouped data or panel data). In both cases, it is appropriate to consider the link between the individual observations within each group by using statistical estimators and models which are suitable for the analysis of this data structure.

Multiple responses from a single individual, as in this case, make it necessary to verify the presence of a correlation that would constitute a violation of the hypothesis of independence of irrelevant alternatives (or IIA) characterizing the classical choice model [36-38]. Moreover, the correlation and 
the heterogeneity of preferences are interdependent and, therefore, it is important to decide how to treat them.

In a Conditional Logit (CL) model there is a randomly selected individual I that chooses repeatedly in $T$ situations between several alternatives $N$. Each alternative accommodates a vector of (non-random) explanatory variables $X_{i n t}$ that are observed by the analyst and include attributes of the alternatives (e.g., price), SECs of the respondent, and descriptors of the decision context and the choice task itself. For the sake of simplicity, an indirect utility function $U_{\text {in }}$ for each alternative $n$ and individual $i$ is assumed to be linear with respect to the variable levels $X_{\text {int }}$. For each alternative, there are utility sensitive elements $\varepsilon_{\text {int }}$ that cannot be observed by the researcher but which are known to the individual. The probability for the individual $i$ to choose the alternative $m$ results from the following formula:

$$
P_{i m t}=\exp \left(\alpha_{i m t}+\beta i X_{i m t}+\varepsilon_{i m t}\right) / \Sigma_{n} \exp ^{\left(\alpha_{i n t}+\beta i X_{i n t}+\varepsilon_{i n t}\right)}
$$

Therefore, in estimating a CL model, the intercept and slope of the parameters are the same for the entire population. In other words, $\varepsilon_{\text {int }}$ should be interpreted as caused by specific changes in each choice exercise with respect to individual preferences. For the sake of simplicity and referred to the baseline situation, independence between different exercises, alternatives, and individuals is assumed. Finally, the condition that $\varepsilon_{\text {int }}$ is independent and identically distributed (IID) with an extreme value type 1 is imposed.

Another important issue is linked to the different presentation of the choice sets. In fact, they can take on two basic forms: with labeled or unlabeled choices. In the former case, the name of the alternatives (which must be highlighted in the task) gains significance for the respondent; while, in the latter, it is not present (or it simply indicates the position within the task); so, the interviewee chooses by looking essentially at the attributes and their levels. From the point of view of the model output that can be pulled out of this type of data, it is worth reminding that some estimates lose their significance while others remain valid (e.g., the willingness to pay). Therefore, unlabeled choice experiments involve the calculation of generic parameters, while labeled ones facilitate the estimation of specific alternatives of choice, which are clearly recognizable in the choice set [18].

Accordingly, modeling the unlabeled choices requires some special care. The first issue has to do with the introduction of alternative-specific constants (ASCs) that capture the mean of the unobserved effects on choices associated with their respective alternatives. In spite of the obvious, that would lead to dropping them, there are no compelling reasons that completely rule out the introduction of one or more constants in the model. The existence of conditional effects or bias when the alternatives are not labeled, has been tested [39] in the literature; i.e., when the respondent places the preference to the answers on the right/left or at the center of the task regardless of the profile content. These biases are manifested regardless of the experimental design. In any case, from a behavioral point of view, the estimation of specific parameters, valid for each alternative, has no relevance in the case of unlabeled choices: if a randomized design is employed, there is no reason to think that the coefficient of price/cost of alternative A is different from that of option B. In this case, if the ASC were statistically significant, it would mean that the behavioral bias would indeed matter.

Finally, it is also worth highlighting that the issue is regarding the introduction of the respondent's SECs in a model that would essentially only contemplate the use of choice attributes. Actually, if a variable remains constant in all alternatives, it becomes impossible to isolate its specific influence: an individual does not change gender or age when choosing between different options; she/he would rather be conditioned to choose certain alternatives (e.g., those characterized by low/high prices). Therefore, there are only two ways to introduce them in the utility function:

1. Inserting the SEC in one of the alternatives; this will signal the difference (if significant) in terms of the presence (or absence) of the variable effect. In this case, the parameter will be interpreted as the marginal utility contribution in the J-1 indirect utility function associated with it, versus those without it. 
2. Creating variables/interaction terms (where a term of interaction is represented by the multiplication of two or more variables), such as, for example, the multiplicative effect of price and household income.

As mentioned before, the CL model poses some restrictions on the error distribution while a more flexible structure is needed in this case, so as to be more adaptable to the experimental design. For example, the Random Parameter Logit (RPL) is characterized by randomness in parameters [40]; it accommodates heterogeneity as a continuous function of the same parameters; the latter are random parameters underlying some ex-ante specified distribution. A random component in the parameters is introduced accordingly:

$$
U_{\text {in }}=\beta^{\prime} X_{\text {in }}+\left[\eta_{\text {in }}+\varepsilon_{\text {in }}\right]
$$

where $\eta_{\text {in }}$ is a random term with zero mean whose distribution over individuals and alternatives generally depends on underlying parameters and observed data relating to an alternative $n$ and individual $i$; and $\varepsilon_{i n}$ is a random term with zero mean that is IID over alternatives and does not depend on underlying parameters or data. For any specific situation, the variance of $\varepsilon_{i n}$ may not be identified separately from $\beta^{\prime}$, so it is normalized to set the scale of utility. Since $\eta$ is not given, the (unconditional) choice probability is the Logit integrated over all values of $\eta$ weighted by its density as in the following equation:

$$
P_{n}=\int L_{n}(\eta) f(\eta \mid \Omega) d \eta
$$

Random parameters are used to capture heterogeneity in preferences through their standard deviation or through the study of the interaction between the mean of the parameters and deterministic segmentation criteria. In these cases, it is assumed that random variables of the indirect utility function are probably not independent from the deterministic ones, and that the variance of the random component is not constant between different individuals or for the same individual over time or in different situations. The choice of the random variables is also linked to how the correlation between alternatives and the choices in different tasks is modeled. Moreover, the choice of distribution for the random parameters is a sensitive point. An inappropriate choice of distribution may lead to bias or counter-intuitive signs in the estimated parameters (The normal distribution is commonly used in RPL models where there is no a priori assumption about the sign of the parameter. The uniform distribution might be a more appropriate choice in the initial search for random taste variation because it has a lower risk of misspecification than less flexible distributions [41]. The log-normal distribution is typically used where the parameter is assumed to be bounded by zero, such as a price attribute.).

The present experiment is based on the hypothesis that there is correlation between choices made by the same individual in different choice exercises (tasks). In addition to that, the experimental design was based on randomized rather than fixed (or specific) alternatives, where the choice should depend only on the product's attributes and its levels. In these cases, it may be difficult to accommodate the characteristics of the consumer into the model. In this sense, RPL can be helpful.

\section{Estimation Process and Results}

Therefore, the estimation model takes into account the aforementioned considerations and tests the following hypotheses:

1. Model fitting can be improved by taking into account the fact that the same individual has carried out four choice exercises and the alternatives are unlabeled;

2. Accommodating the effect of some SECs (Variables pertaining to the individual and employed in the model were measured as follows: SCHOOL_LEV (Educational level; ordinal: $1=$ "primary level"; 2 = "high school level"; 3 = "first degree level"; 4 = "master or Ph.D. level"); INCOME (Household net monthly income; ordinal: $1=$ "lower than $600 € /$ month"; 2 = "from 601 to 1200 "; $3=$ "from 1201 to $1800 " ; 4=$ "from 1801 to $2400 " ; 5=$ "from 2401 to $3000 " ; 6=$ "from 3001 to $3600 " ; 7$ = "form 3601 to $4200 " ; 8=$ "from 4201 to $4800 " ; 9$ = "more than 4800 "); AGE (Age of the 
individual; ordinal: 1 = "from 18 to $30 " ; 2=$ "from 31 to 45 "; $3=$ "from 45 to 65 "; $4=$ "more than 65"); OWNRENT (desired home tenure; dichotomous; 1 = "owner"; $0=$ "renter"). Instead, as explained in Section 3.3, OWNRENT_PRC and INCOME_PRC are the multiplicative interaction effects between ownership and individual income with price overcharging, taking the assumption that marginal WTP is compensated by income and that individuals willing to own their home are more prompt to pay for energy performance improvements.) constitutes a necessary step; in particular, the hypothesis tested is that the building's energy performance has a negative perception by the consumer and that his/her education level (SCHOOL_LEVEL) increases the possibility to understand the economic and environmental consequences of his/her choice.

3. The different behavior of owners and renters is firstly tested by means of the dichotomous variable OWN_RENT.

4. Finally, the distribution of some parameters could be random and the marginal willingness to pay (WTP) for different demand segments could be an interesting output. Moreover, the estimators of the WTP elicited and the marginal WTP inferred by the choice experiment should converge.

The findings in Table 1 are referred to as the final (reduced) version of the model. The presence of a behavioral bias on the unlabeled alternative two was found; in other words, sometimes, the attention of the respondent was focused on the center of the choice set, regardless of the attributes and their levels. It should be noted that the simple accounting of this bias improved the model performance with an increment of the overall explained variation.

In a RPL model, each random attribute has both an unconditional mean and a derived standard deviation computed by means of simulation. In a panel (grouped) version of the RPL, as used in this experiment, some parameters vary between individuals (SCHOOL_LEV) but they are fixed across choices made by the same individual. After some tests, the best distribution of the random parameters was found to be the normal distribution. Some SECs are instead entered as interaction terms, essentially with price overcharging (OWNRENT_PRC and INCOME_PRC). Their effect is statistically significant at $5 \%$. Conversely, some of the parameters (nonrandom) of choice attributes are not statistically significant. The presence of condominium amenities or additional private spaces does not seem to be important for the respondent, while active conditioning (ACT_COND), quality of finishings (QUAL_FIN), and price charging (PRICE_CH) are.

Table 1. Random Parameters Conditional Logit Model-Estimation results.

\begin{tabular}{|c|c|c|c|c|c|c|}
\hline Dep Variable: CODE_CHO & Coefficient & St. Error & $z$ & Sign & \multicolumn{2}{|c|}{ Interval } \\
\hline \multicolumn{7}{|c|}{ Random Parameters in Utility Functions } \\
\hline SCHOOL_LEV & $0.020297 * * *$ & 0.06728 & 3.02 & 0.0026 & 0.07109 & 0.33484 \\
\hline INC_PRC & $0.0022 * * *$ & 0.00064 & 3.45 & 0.0006 & 0.00095 & 0.00345 \\
\hline \multicolumn{7}{|c|}{ Nonrandom parameters in utility functions } \\
\hline QUAL_FIN & $2.44387^{* * *}$ & 0.68301 & 3.58 & 0.0003 & 1.10519 & 3.78254 \\
\hline ACT_COND & $0.31875^{* * *}$ & 0.08337 & 3.82 & 0.0001 & 0.15535 & 0.48215 \\
\hline ENERGY_E & $-1.96061^{* * *}$ & 0.28485 & -6.88 & 0.0000 & -2.5189 & -1.40233 \\
\hline ENERGY_A & $1.09087^{* * *}$ & 0.16717 & 6.53 & 0.0000 & 0.76323 & 1.41852 \\
\hline PRICE_CH & $-0.07078^{* * *}$ & 0.01413 & -5.14 & 0.0000 & -0.10025 & -0.04488 \\
\hline OWNRENT_PRC & $0.00489 * *$ & 0.00241 & 2.03 & 0.0426 & 0.00016 & 0.00961 \\
\hline A2 (CONSTANT 2) & $-0.7078 * *$ & 0.28013 & -2.53 & 0.115 & -1.25686 & -0.15875 \\
\hline \multicolumn{7}{|c|}{ distances of parameters. Std. Devs or limits of triangular } \\
\hline SCHOOL_LEV & 0.16236 & 0.03609 & 4.50 & 0.0000 & 0.09162 & 0.23309 \\
\hline INC_PRC & 0.00223 & 0.00047 & 4.74 & 0.0000 & 0.00131 & 0.00315 \\
\hline
\end{tabular}


Finally, respondents still evaluate the EPC EL rank as relevant; the unconditional estimate of WTP to shifting from an intermediate position $(\mathrm{C})$ to a worse $(\mathrm{E})$ is equal to $€-27.70$, while moving to a better class $(\mathrm{A})$ is equal to $€ 15.41$. The random effect of the respondent's educational levels was taken into account. In relation to other attributes, it must be highlighted that the EL seems to count more than active conditioning systems (ACT_COND) but less than the quality of finishings (QUAL_FIN); although this latter variable, the most important driver of choices, is conditional to price charging, so it may be proxying for this variable as well.

Figure 2 shows the variation of the WTP (E-A) estimate for the four educational level groups of the population. The conditional means are, in this case, equal to $€-24.21$ and $€ 17.84$.

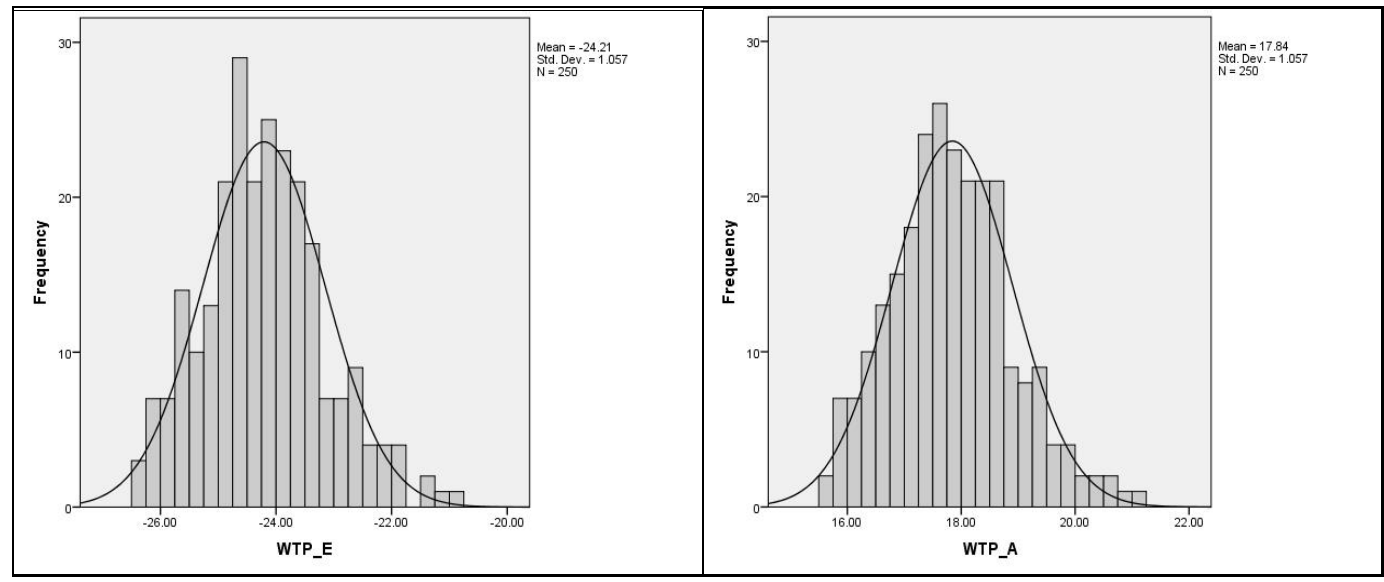

Figure 2. Random (normal) distribution of WTP from EL switching $(\mathrm{C} \rightarrow \mathrm{E}$ and $\mathrm{C} \rightarrow \mathrm{A})$. Source: Authors' compilation.

In this regard, it is worth reminding that the questionnaire included a close-ended question with follow-up about WTP to switch from Class E to Class A, for a standard three-room city apartment and against a savings on the electricity/gas bill. The estimated mean is, in this case, equal to $€ 25.92$ due to a high presence of zero (or lack of willingness to pay for the offered EL rank improvement). The regression results (Table 2) confirm that WTP, as a censored variable, is influenced by the SECs, particularly income, age, and educational level, but also by the individual's desire to become the owner/renter of the offered apartment. These findings appear to be consistent with those elicited by the choice experiment.

Table 2. Censored regression model (Tobit)-Estimation results.

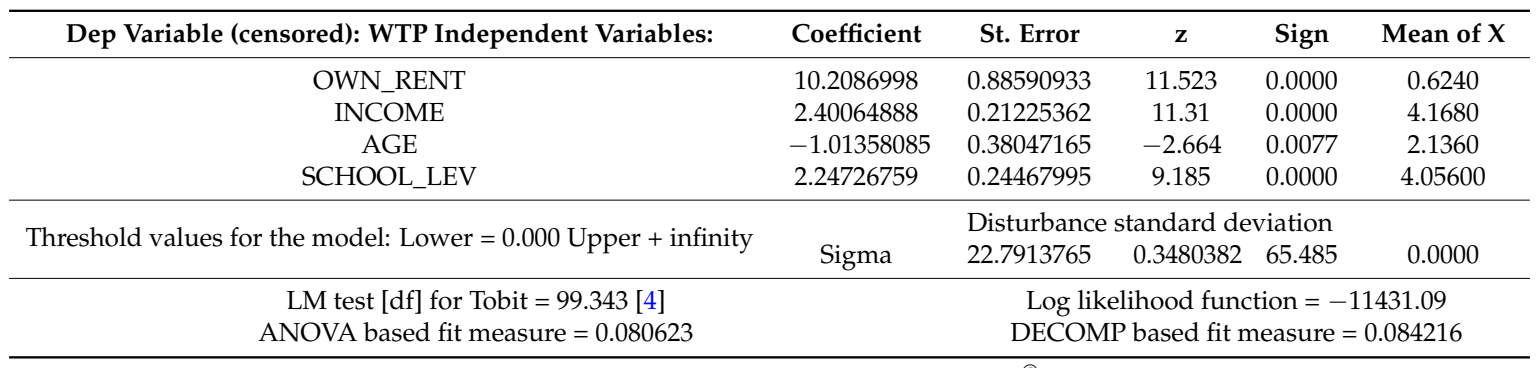

Source: Authors' compilation with NLogit $6^{\odot}$.

More generally, the estimated model underlines the importance of segmentation and correct accommodation of the variation explained by the SECs. Understanding of individual/group behavior is already informing European policy-making and contributing to the design of new forms of intervention, as well as complementing traditional approaches [42]. Since in the field of environmental 
policies related to the residential market, the extension of home ownership prevented massive public interventions on the building's energy performance, it is important to identify some discriminants of families' and individuals' behavior and preferences. In fact, regulations and incentives may not have the same effects on consumer choices when benefits/costs are not well perceived or are considered differently by distinct individuals/groups.

Moreover, impacts of buildings' energy performance on the environment are probably better considered when individuals anchor their choices on cultural/moral satisfaction. Since improvements in the energy performance of the existing residential stock are, in most cases, expensive and regulations on new constructions and ad hoc incentives can only generate a limited impact, education and information on energy consumption become decisive to drive change.

\section{Discussion and Conclusions}

Starting from the hypothesis that, in real estate markets, the EL is not an isolated attribute influencing choices and prices, and its economic value rather represents a trade-off with other building characteristics, a choice based experiment was implemented in Barcelona. From this analysis, some methodological and empirical conclusions can be drawn.

From a methodological standpoint, the evolution of the modeling related to consumer choice allows us to solve some problems as of today, related mainly to the random component inside the model. The experiment reported here shows that taking into account the true sample structure, consisting of individuals who perform multiple tasks, improves the model fitting, and detects some biases, definitely reducing the estimated error. Furthermore, RPL specifications, through the relaxation of the IIA assumption, enable the model to be specified in such a way that the choice sets can be correlated across each individual.

From an empirical standpoint, the EPC EL classification seems to exert an important influence in the choice of a city apartment. As a matter of fact, the EL class appears to be more relevant in the respondents' preference structure in relation to other architectonic features such as active climatic conditioning, or even, condominium amenities and additional private spaces. This finding is relevant by itself: firstly, because Barcelona benefits from a mild Mediterranean weather where possible energy savings derived from efficient buildings are less important in relation to other climatic zones; and secondly, because the implementation of the EPC policy is quite recent and has not been accompanied by a specific dissemination campaign regarding its implications. Perhaps the use of illustrative units of financial impact (monthly savings in energy bills) and environmental implications (equivalent $\mathrm{CO}_{2}$ produced by a car), instead of legal ones $\left(\mathrm{kW} / \mathrm{h} / \mathrm{m}^{2} /\right.$ year and tons of $\mathrm{CO}_{2} / \mathrm{m}^{2} /$ year) may have played a role. Nevertheless, these findings contrast with those of Heizle et al. [15], where the EL was less important than other locative attributes.

More specifically, individuals' educational level is linked to the awareness and previous knowledge of the building's energy performance. The role that the level of education seems to play in the choice tasks suggests than more emphasis should be placed on the dissemination of the EPC scheme in Spain. The legislation (RD 235/2013) transposing the EPBD (2002/91/CE; 2010/31/UE) does not include any indication regarding the need to disseminate and raise awareness regarding the relevance, meaning, nor economic/environmental implications of energy efficiency in buildings as measured in the EPC EL. Nor has the administration made any specific effort to translate this information in a way that would be understandable by the final point of demand, especially for the less educated segment.

However, the sample interviewed showed an appreciation for this attribute and indicated a positive/negative WTP in case of improvement/deterioration of the building condition. According to the model, a shift from a Class " $\mathrm{E}$ " (the minimum classification granted to new dwellings according to the national building regulation CTE) to a Class " $\mathrm{A}$ " apartment would imply a WTP equivalent to 43.11 Euros/month, which is roughly higher that the stated savings in energy bills equivalent to 30 Euros/month. That means that if hypothetical bias is not important, individuals are ready to pay 
above the financial benefits associated to the energy efficiency in buildings. Such surplus may be linked to other non-financial benefits of efficient buildings such as the offered reduction in $\mathrm{CO}_{2}$ emissions, which, in turn, may imply the existence of environmental concerns. This finding is in keeping with other investigations where energy efficiency in buildings was also linked to environmental concerns $[8,11,12]$.

Finally, a different attitude on behalf of the owners, contrasted with that of the tenants, was identified in terms of their interaction with price charging. In other words, people seeking to rent the offered apartment seem less willing to pay than people seeking to buy it, even when presented with possible energy benefits. Although this appears consistent with the assumptions on consumer behavior, all the same, it raises important concerns regarding public policy. As energy policy is linked to savings or public incentives, it should take into account not only the characteristics of the current housing stock, but also the housing market structure. For example, if renters are more price-sensitive), then property owners could be less interested in energy saving investments, and rented property could, in time, end up in a poor state from this point of view. Thus, these results suggest the necessity to integrate environmental policies in the broader and more complex framework of housing policy.

Acknowledgments: This work is funded by EnerValor project grant BIA 2015-63606-R (MINECO/FEDER); both Authors are part of the research team.

Author Contributions: First Author conceived, designed and performed the experiment, while the second analyzed data and applied the model; both Authors wrote the paper; thank you to Rosa García Ramos for her help in designing the experiment.

Conflicts of Interest: The Authors declare no conflicts of interest.

\section{References}

1. García-Navarro, J.; Díaz, M.; Valdivieso, M. «Estudio Precost\&e»: Evaluación de los costes constructivos y consumos energéticos derivados de la calificación energética en un edificio de viviendas situado en Madrid. Informes de la Construcción 2014, 66, 535. (In Spanish). [CrossRef]

2. Marmolejo, $\mathrm{C}$. The incidence of the energy rating on residential values: an analysis for the multifamily market in Barcelona. Informes de la Construcción 2016, 68, 543. (In Spanish). [CrossRef]

3. Bottero, M.; Bravi, M.; Mondini, G.; Talarico, A. Building energy performance and real estate market value: An application of the Spatial Autoregressive (SAR) model. In Appraisal: From Theory to Practice, Green Energy and Technology; Stanghellini, S., Morano, P., Bottero, M., Oppio, A., Eds.; Springer: Cham, Switzerland, 2017; pp. 221-230.

4. Brounen, D.; Kok, N. On the economics of energy labelling in the housing market. J. Environ. Econ. Manag. 2011, 62, 166-179. [CrossRef]

5. Hyland, M.; Lyons, R.; Lyons, S. The value of domestic building energy efficiency: Evidence from Ireland. Energy Econ. 2013, 40, 943-952. [CrossRef]

6. Mudgal, S.; Lyons, L.; Cochen, F. Energy Performance Certificates in Buildings and Their Impact on Transaction Prices and Rents in Selected EU Countries; Bio Intelligence Service Working paper; Bio Intelligence Service: Paris, France, April 2013.

7. Fuerst, F.; McAllister, P.; Nanda, A.; Wyatt, P. Does energy efficiency matter to home-buyers? An investigation of EPC ratings and transaction prices in England. Energy Econ. 2015, 48, 145-156. [CrossRef]

8. Poortinga, W.; Steg, L.; Vlek, C.; Wiersma, G. Household preferences for energy-saving measures: A conjoint analysis. J. Econ. Psychol. 2013, 24, 49-64. [CrossRef]

9. Sadler, M. Home Energy Preferences \& Policy: Applying Stated Choice Modelling to a Hybrid Economy Model; Ph.D. Thesis, Simon Fraser University, Burnaby, BC, Canada, September 2003.

10. Achtnitcht, M.; Madlener, R. Factors influencing German house owners' preferences on energy retrofits. Energy Policy 2014, 68, 254-263. [CrossRef]

11. Banfi, S.; Farsi, M.; Filippini, M.; Jakob, M. Willingness to pay for energy-saving measures in residential buildings. Energy Econ. 2008, 30, 503-516. [CrossRef]

12. Kwak, S.Y.; Yoo, S.H.; Kwak, S.J. Valuing energy-saving measures in residential buildings: A choice experiment study. Energy Policy 2010, 38, 673-677. [CrossRef] 
13. Achtnitcht, M. Do environmental benefits matter? Evidence from a choice experiment among house owners in Germany. Ecol. Econ. 2011, 70, 2191-2200. [CrossRef]

14. Farsi, M. Risk aversion and willingness to pay for energy efficient systems in rental apartments. Energy Policy 2010, 38, 3078-3088. [CrossRef]

15. Heinzle, S.; Ying, A.; Xing, M. The influence of green building certification schemes on real estate investor behaviour: Evidence from Singapore. Urban Stud. 2013, 50, 1970-1987. [CrossRef]

16. Addae-Dapaah, K.; Chiech, S. Green mark certification: Does the market understand? J. Sustain. Real Estate 2011, 3, 162-191.

17. Zalajeska-Jonsson, A. Impact of energy and environmental factors in the decision to purchase or rent an apartment: The case of Sweden. J. Sustain. Real Estate 2014, 5, 66-85.

18. Hensher, D.A.; Rose, J.M.; Greene, W.H. Applied Choice Analysis; Cambridge University Press: Cambridge, UK, 2015.

19. McFadden, D. Conditional Logit analysis of qualitative choice behaviour. In Frontiers in Econometrics; Zarembka, P., Ed.; New York Academic Press: New York, NY, USA, 1974; pp. 105-142.

20. Ajzen, I. The theory of planned behavior. Organ. Behav. Hum. Decis. Process. 1991, 50, 179-211. [CrossRef]

21. Ehmke, M.; Lusk, J.; List, J. Is hypothetical bias a universal phenomenon? A multinational investigation. Land Econ. 2008, 84, 489-500. [CrossRef]

22. List, J.; Gallet, C. What Experimental protocol influence disparities between actual and hypothetical stated values? Evidence from a meta-analysis. Environ. Resour. Econ. 2001, 20, 241-254. [CrossRef]

23. Natural Resource Damage Assessment: Proposed Rules; National Oceanic and Atmospheric Administration: Washington, DC, USA, 1994. Available online: https:/ /www.fws.gov/policy/NRDA-2.pdf (accessed on 14 June 2017).

24. Natural Resource Damage Assessment: Final Rules; National Oceanic and Atmospheric Administration: Washington, DC, USA, 1996. Available online: https:/ /www.fws.gov/policy/NRDA-2.pdf (accessed on 14 June 2017).

25. Fifer, S.; Rose, J.; Greaves, S. Hypothetical bias in stated choice experiments: Is it a problem? And if so, how do we deal with it? Transp. Res. Part A 2014, 61, 164-177. [CrossRef]

26. Landry, C.; List, J. Using ex ante approaches to obtain credible signals for value in contingent markets: Evidence from the field. Am. J. Agric. Econ. 2007, 89, 420-429. [CrossRef]

27. Cummings, R.; Taylor, L. Unbiased value estimates for environmental goods: A cheap talk design for the contingent valuation method. Am. Econ. Rev. 1999, 89, 649-665. [CrossRef]

28. Hofler, R.; List, J. Valuation on the frontier: Calibrating actual and hypothetical statements of value. Am. J. Agric. Econ. 2004, 86, 213-221. [CrossRef]

29. List, J.; Sinha, P.; Taylor, M. Advances in economic analysis \& policy. Field Exp. 2006, 6, 1-37.

30. Marmolejo, C.; Ruiz, M. Using choice-based-experiments to support real estate design decision. J. Eur. Real Estate Res. 2013, 6, 63-89. [CrossRef]

31. Earnhart, D. Combining revealed and stated data to examine housing decisions using discrete choice analysis. J. Urban Econ. 2012, 51, 143-169. [CrossRef]

32. Kastner, I.; Stern, P.C. Examining the decision-making processes behind household energy investments: A review. Energy Res. Soc. Sci. 2015, 10, 72-89. [CrossRef]

33. Roca, J. La Estructura de Valores Residenciales: Un Análisis Teórico y Empírico; Instituto de Estudios de Administración Local: Madrid, Spain, 1988.

34. Barboza, M. Evaluación de Costes y Beneficios de una Mayor Cualificación Energética Enthe el Mercado Residencial de Nueva Planta en Barcelona. Master's Thesis, Universitat Politècnica de Catalunya, Barcelona, Spain, July 2016.

35. Orme, B.K. Fine-Tuning CBC and Adaptive CBC Questionnaires; Research paper series; Sawtooth Software: Orem, UT, USA, 2009.

36. Bradley, R.A.; Terry, M.E. Rank analysis of incomplete block designs: I. The method of paired comparison. Biometrika 1952, 39, 324-345. [CrossRef]

37. Luce, R.D. Individual Choice Behavior; Wiley: New York, NY, USA, 1959.

38. Marschak, J. Binary choice constraints and random utility indicators. In Mathematical Methods in the Social Sciences; Arrow, K.J., Karlin, S., Suppes, P., Eds.; Stanford University Press: Bloomington, IN, USA, 1959.

39. Carp, F.M. Position effects on interview responses. J. Gerontol. 1974, 29, 581-587. [CrossRef] [PubMed] 
40. Hensher, D.A.; Greene, W.H. Mixed logit models: State of practice. Transportation 2003, 30, $133-176$. [CrossRef]

41. Hess, S.; Polak, J.W. Mixed Logit modelling of airport choice in multi-airport regions. J. Air Transp. Manag. 2005, 11, 59-68. [CrossRef]

42. European Commission's Joint Research Center. Behavioural Insights Applied to Policy; European Report; Joint Resarch Centre: Ispra, Italy, 2006; Available online: http:/ / publications.jrc.ec.europa.eu/repository/ bitstream/JRC100146/kjna27726enn_new.pdf (accessed on 5 November 2016).

(C) 2017 by the authors. Licensee MDPI, Basel, Switzerland. This article is an open access article distributed under the terms and conditions of the Creative Commons Attribution (CC BY) license (http:/ / creativecommons.org/licenses/by/4.0/). 